\title{
RESOURCE DEPENDENCY, INSTITUTIONAL, AND STAKEHOLDER ORGANIZATIONAL THEORIES IN FRANCE, NIGERIA, AND INDIA
}

\author{
Samuel O. Fadare ${ }^{1}$ \\ 'School of Business \& Leadership, Regent University
}

\begin{abstract}
This paper describes resource dependency, institutional and stakeholder organizational theories and how each theory might or might not work in the France, Nigeria, and India. Application of the three organizational theories demonstrates several features, including an emphasis on inter-organizational dependence for organizational survival and resolution of issues of conflicts between competing stakeholders as critical to the sustenance of organizations in all three national cultures. In relation to the institutional theory, while France is required to implement all European Union Directives and constantly put organizations under pressure to conform to these expectations, issues of poverty, nepotism, political godfatherism, and corruption prevalent in India and Nigeria mean that organizations are not always put under as much pressure to conform to expectations.
\end{abstract}

Keywords: Organization, Culture, Resource dependency, Institutional, Stakeholder.

Received: 30 October 2013/ Revised: 27 November 2013/ Accepted: 2 December 2013/ Published: 10 December 2013

\section{INTRODUCTION}

This paper describes resource dependency, institutional, and stakeholder organizational theories and compares/contrast the application of the three organizational theories in France, Nigeria, and India. In practice, a number of issues are readily identifiable with the application of each theory in the three national cultures. With the coercive mechanism of institutional isomorphic change for example, issues of poverty, nepotism, political god-fatherism, and corruption prevalent in Nigeria and India mean that organizations in the two countries are not always under as much pressure to conform to expectations. With the stakeholder theory, it is not uncommon to find that one group of stakeholders are made better off at the detriment of another group of stakeholders in the same organization. For example, issues of rising executive compensation vis-à-vis closing down of plants and offshoring of production processes by French organizations to India is rampant. In India, issues of child labor, long hours, poor wages, and inhuman working conditions are common place in its many factories. These factories make products that cater for the super rich of Europe and America. In Nigeria, while companies such as Royal Dutch Shell make a significant proportion of their income from Nigeria, oil spills, deforestation and gas flaring has meant that the oil producing Niger Delta region of the country is virtually inhabitable with water ways, the air, and farms polluted.

In its broadest sense, Pugh (1973) defined organization theory as the systematic "study of the structure, functioning and performance of organizations and the behavior of groups and individuals within them" (p. 9). Fuhs (2009) described organization theory as an interdisciplinary and complex array of concepts and approaches that investigates knowledge from diverse fields including economics, sociology, political science, psychology, ecology, cultural studies, and linguistics (p. 1). These two definitions suggest a multidisciplinary and interdisciplinary phenomenon that permits information processing through the interaction of variables within and outside the environment of the organization. 
The study and knowledge of early organization theories provide a solid platform from which to build more modern organization theories. Increased globalization, economic integration, technological advancement, and complexity of today's organizations has put additional burden on organizations to develop more relevant theories with practical application in today's workplace. According to Dooley (1997), organizational theories of the nineteenth and early twentieth centuries pioneered by management theorists such as Fayol and Taylor which were synonymous with bureaucracies, hierarchies and structures, are no longer relevant for today's organizations as they were deterministic and rigid. (p. 70). Lichtenstein et al. (2006) argued that while traditional, hierarchical views of leadership were relevant for earlier and simpler forms of organizations, the complexities of modern organizations mean that leadership and leadership styles must change in order to keep pace with the "complex adaptive needs of organizations... [as]...leadership is a dynamic that transcends the capabilities of individuals alone; it is the product of interaction, tension, and exchange rules governing changes in perceptions and understanding" (p. 2).

Using France, Nigeria, and India, three of the regions used as part of the GLOBE Project, and three organizational theories presented by Hatch (2013), this paper describes how each theory might or might not work in the three different cultures. The remainder of this paper presents a description of three organizational theories: (a) resource dependency, (b) institutional, and (c) stakeholder organizational theories. The paper concludes by providing a synopsis, recommendations and an outline of possible areas of future research.

\section{ORGANIZATIONAL THEORIES}

Starting with the Scientific Management theory, a myriad of organizational theories have emerged over the last 100 years; these theories provide one or more solutions to real organizational and leadership issues. Laegaard and Bindslev (2006) however explained that "future organizations must be capable of changing relative to changeable world" (p. 10). Thus, while some reliance can be placed on these organizational theories, attempts should be made to develop newer and more relevant organizational theories. This paper will focus on three of such organizational theories i.e. resource dependency, institutional, and stakeholder organizational theories and their application to the national cultures of France, Nigeria, and India.

\subsection{Resource Dependency Organizational Theory}

The central thesis of resource dependency theory is that all organizations rely on resources from their environment. These resources are in the hands of other organizations within the environment. Holders of these resources are able to exert power and control over organizations that require the resources. Thus, organizations must depend on each other for exchange and survival. According to Pfeffer and Salancil (1978), resource dependency theory argues that "the key to organizational survival is the ability to acquire and maintain resources" (p. 2). Hatch (2013) expands on this definition by explaining that an organization's reliance on its environment is a function of "its need for resources such as raw materials, labor, capital, equipment, and outlets for its products and services" (p. 70). In other words, the environment is able to assert influence over organizations' through elements as "competitive process, desirable products and services, and efficient organizational structures and processes” (p. 70).

This suggests an organization cannot survive if it is unable to guarantee the continuous supply of resources critical to its survival. Using a predictive model of resource dependency, Sheppard (1995) found significant, consistent positive relationships between organizational survival and the present level of an organization's resources, influence with critical resource providers, and the stability of organizations' environment (p. 28). Pfeffer and Salancil (1978) suggest that organizations should ensure their survival by management of demands, particularly the demands of interest groups upon which the organizations depend for resources and support..." (p. 2). Other strategies suggested by them include retaining multiple sources of supply, creating joint ventures, vertical integration with suppliers, horizontal integration with competitors, and marketing (Hatch, 2013).

Dorfman et al. (2012) explained that quantitative results of the GLOBE Project for SubSaharan Africa (SSA) suggest that human interdependence and the strive for harmony in all social relations were important organizational and leadership characteristics in the Sub-Saharan region or societies of Nigeria, Namibia, Zambia, Zimbabwe and South Africa (Black sample). The authors 
added that SSA orientation reflected traditions such as reciprocity in social relations and team work. (p. 6). The identified orientations as relates to SSA countries in general and Nigeria in particular, resonates with the requirements for resource dependence. The approach is quite different within French-based Organizations as they manage resource dependence by efficient supply chain management to avoid stock-outs, and maintenance of databases of alternative suppliers of similar goods and services. This is to ensure that they are not held to ransom or disappointed if a supplier fails to deliver as agreed. Organizations in the country also form alliances, particularly with countries in the European Union for the supply of such items as beef and milk at controlled prices. According to the GLOBE Project, interdependence was one of the strong attributes of the Latin European country.

Unlike France, India's approach to resource dependence is quite similar to that of Nigeria. As a result of India comparative advantage in terms of its population, and relatively low labor costs, organizations from across the world regularly establish factories in Indian cities to take advantage of relatively lower production costs and labor resources as well as a ready market for products. According to the Indian Ministry of Internal Affairs, as published in http://www.censusindia.gov.in, there were over 1.24 billion Indians on planet earth as at March 1, 2011; this represented just over 17 per cent of the total population of the world (second only to China with 1.34 billion people). Pfeffer (1987) argued that since organizations are not autonomous, but rely on a network of interdependences with other organizations, organizations are necessary in order to understand inter-corporation relations and within the society.

\subsection{Institutional Organizational Theory}

Institutional theory of organization is an extension of resource dependence theory. Hatch (2013) explained that although organizations require resources such as raw materials, capital and labor to survive, organizations that have all these resources but lack acceptance of the societies in which they operate - regulators, government agencies, laws and courts, professions, interest groups, and mobilized public opinion - will end up failing. Thus in an input-output model, an organization must have inputs such as raw materials, labor, capital, equipment as well as social legitimacy to be able to generate outputs. (p. 74). DiMaggio and Powell (1983) described three mechanisms of institutional isomorphic change that support the repeated activities of institutions "(1) coercive isomorphism that stem from political influence and the problem of legitimacy; (2) mimetic isomorphism, resulting from standard responses to uncertainty; and (3) and normative isomorphism, associated with professionalization institutional mechanisms" (p. 150).

As explained above, the three mechanisms of institutional isomorphic change derive from different conditions, as a result of this, outcomes may differ. The different conditions and how the outcomes may differ in the three national cultures are explained below.

Coercive Isomorphism: France is member country of the European Union and is required to implement all European Union Directives. In order for it and organizations within the country to avoid breaching any of these Directives, the French government enact regulations and laws that replicate those of the European Union and constantly put organizations under pressure to conform to these expectations. DiMaggio and Powell (1983) explained that "the existence of a common legal environment affects many aspects of an organization's behavior and structure" (p. 150). Quite different from how the coercive mechanism works in France, governments at all levels in Nigeria and India put in place regulations and laws and also establish agencies to enforce these regulations and laws; however, due to issues of poverty, political god-fatherism, and corruption prevalent in both countries, organizations are not always put under as much pressure to conform to expectations.

Dorfman et al. (2012) reported that one of the dominant and negative forces found about subSaharan Africa as part of the thematic findings of the GLOBE Project was: that of a culture of corruption, poverty, tribalism and violence which unfortunately persists in many SSA countries. This culture includes a negative view of organizational and political leaders as well as low personal aspirations and feelings of helplessness resulting in a tolerance of corruption, nepotism and occasional acts of violence. These factors contribute to the emergence of the "African Strong Man" who imposes his will on populations, enriches himself and his in-group at the people's expense, and uses any 
means possible to retain his power. The prototypical "African Strong Man” is clearly an important factor contributing to the continuing social problems in SSA today. (p. 7).

Mimetic Isomorphism: According to Hatch (2013), institutional pressures to be perceived as being successful may lead organizations to pretend as if they indeed are successful. (p. 75). DiMaggio and Powell (1983) posit that when organizational technologies are poorly understood, when goals are ambiguous, or when the environment creates symbolic uncertainties, for example, such situations of uncertainties encourage imitation. (p. 151). In Nigeria and India, because of the constant state of uncertain in its politics and policies, organizations in the two countries are often very inventive with resources. For example, rather than import replacement parts for its machineries and other equipment, organizations in both countries locally fabricate replacement parts and make use of alternative production processes. This decision is often driven by ambiguity over foreign exchange rules. The uncertainty over the final cost of importation of these replacement parts also prevents organizations from important as the final cost of importation has a direct cost implication on finished goods to consumers. The status described above for Nigeria and India is different in France as the environment and information within it is near certain. Examples of poorly understood technologies or an uncertain environment does not apply, thus, mimetic institutional pressures are not common place with French organizations.

Normative Isomorphism: This is institutional pressure brought about from professionalism. DiMaggio and Powell (1983) defined professionalism "as the collective struggle of members of an occupation to define the conditions and methods of their work, to control the production of producers" (p. 152). Hatch (2013) extended this definition of professionalism by including cultural expectations such as "the education or religious beliefs of organizational members". (p. 75). All organizations have a mix of professionals and non-professionals who work for them. While in France, there is a clear line between where the duties and responsibilities of professionals and non-professionals start and stop, this is not so clear in reality in Nigeria and India. In France, laws and regulations strengthen professions, indeed, DiMaggio and Powell (1983) explained that "professions are subject to the same cohesive and mimetic pressures as are organizations" (p. 152). In Nigeria and India on the other-hand, cultural and traditional institutions make such pressures on professionals even much higher. For instance, it is not uncommon to have a traditional medical practitioner or herbalist store occupying a building next to a standard hospital or pharmacy store. The consequence is that professionals may be forced to compromise on standards as governments in these two countries recognize both professional and non-professional medical practitioners.

\subsection{Stakeholder Organizational Theory}

Freeman (1984) defined a stakeholder as "any group or individual who can affect or is affected by the achievement of the organization's objectives" (p. 46). Freeman (2004), expanded on this by explaining that a narrow definition of stakeholders implies "those groups who are vital to the survival and success of the corporation... [while] the wide definition of stakeholders includes any group or individual who can affect or is affected by the corporation" (p. 42). In terms of how the stakeholder theory affects organizations, Hatch (2013) explained that "organizations that attend to the demands of all stakeholders will outperform organizations that ignore some of their stakeholders while priveleging others" (p. 82). An example of the explanation provided by Hatch (2013) is the enhancement of shareholders wealth while simultaneausly causing the pollution of local air or water supply.

In France, issues of rising executive compensation vis-à-vis closing down of plants and offshoring of research and development as well as production processes to India are rampant. The recurring explanation for this strategy is the stiff competition from the United States and United Kingdom and the cost savings associated with outsourcing work to India. Examples of French companies that now have a significant presence in India include Atos Origin and Capgemini, both, multi-billion dollar information technology services and consultancy companies. The scenerio painted above is the same in India and Nigeria. In India, issues of child labor, long hours, poor wages, and in-human working conditions are common place in its many factories. These factories make such items as cloths, shoes, and jewelries for the top shops that cater for the super rich of Europe and America. Again, the story gets worse in Nigeria. According to United Nations estimate, the population of Nigeria as at July 2013 was approximately 173.6 million people, making it the seventh most populated country in the world and a mass market for goods and 
services. The country is also the twelfth largest producer of petroleum in the world. However, while companies such as Royal Dutch Shell make a significant proportion of its income from Nigeria, serious oil spills, deforestation and gas flaring has meant that the Niger Delta, the region of the country that produces the oil, is virtually inhabitable with water ways, the air, and farms polluted.

\section{CONCLUSION}

The author began this paper by providing alternative definitions of organizational theory. The definitions suggest a framework which allows for information processing through the interaction of variables within and outside the environment of the organization. Using France, Nigeria, and India, the paper describes three organizational theories contained in Hatch (2013) and explains how each of the three theories currently applies to the three national cultures. Our review demonstrates several features and issues.

1. All three national cultures depend on resources from within their environment for survival.

However, while French-based organizations manage their resource dependence through efficient supply chain management and the maintenance of databases of alternative suppliers of similar goods and services within the European Union. Organizations based in Nigeria are more reliant on personal and human interdependence and existence social or cultural social relations to maintain essential resources.

2. In relation to the institutional theory, while France is required to implement all European Union

Directives and constantly put organizations under pressure to conform to these expectations,

Issues of poverty, nepotism, political god-fatherism, and corruption prevalent in India and

Nigeria means that organizations are not always put under as much pressure to conform to expectations.

3. On the stakeholder theory, the three national cultures grapple with issues of conflicts between

competiting stakeholders.

In terms of possible future extension of this paper, it would be interesting to investigate the effect of other modern organizational theories on the three national cultures and other cultures within varying regions. An investigation to test the empirical effectiveness of the three theories across the three national cultures will also be desirable.

Funding: This study received no specific financial support.

Competing Interests: The author declares that there are no conflicts of interests regarding the publication of this paper.

\section{REFERENCES}

DiMaggio, P. and W. Powell, 1983. The iron cage revisited: Institutional isomorphism and collective rationality in organizational fields. American Sociological Review, 48(2): 147-160

Dooley, K.J., 1997. A complex adaptive systems model of organizational change. Nonlinear Dynamics, Psychology, and Life Sciences, 1(1): 69-97.

Dorfman, D., M. Javidan, P. Hanges, A. Dastmalchian and R. House, 2012. Globe: A twenty year journey into the intriguing world of culture and leadership. Journal of World Business. DOI 10.1016/j.jwb.2012.01.004.

Freeman, R., 1984. Strategic Management: A Stakeholder Approach. Boston: Pitman Publishing Inc.

Freeman, R., 2004. A stakeholder theory of modern corporations. 7th Edn.: Ethical Theory and Business.

Fuhs, C., 2009. Toward an integral approach to organization theory: An integral investigation of three historical perspectives on the nature of organizations. Available from http://www.clintfuhs.com

Hatch, M., 2013. Organization theory: Modern, symbolic, and postmodern perspectives. 3rd Edn., Oxford.

Laegaard, J. and M. Bindslev, 2006. Organizational theory. Ventus Publishing ApS. ISBN: 87-7681-169-7

Lichtenstein, B., M. Uhl-Bien, R. Marion, A. Seers, J. Orton and C. Schreiber, 2006. Complexity leadership theory: An interactive perspective on leading in complex adaptive systems. Emergence: Complexity and Organization, 8(4): 2-12. 
Pfeffer, J., 1987. A Resource Dependence Perspective on Interorganizational Relations. In M. S. Mizruchi, \& M. Schwartz (Eds.), Intercorporate Relations: The Structural Analysis of Business: Cambridge,

UK: Cambridge University Press. pp: 22-55.

Pfeffer, J. and G.R. Salancil, 1978. The external control of organizations. A resource dependence perspective. Harper and Row, New York.

Pugh, D., 1973. Organization theory: Selected readings. Harmondsworth, England: Penguin Books

Sheppard, J.P., 1995. A resource dependence approach to organizational failure. Social Science Research, 24(1): 28-62.

\section{BIBLIOGRAPHY}

House, R.J., P.J. Hanges, J. M., P.W. Dorfman and V. Gupta, 2004. Culture leadership and organizations: The GLOBE study of 62 societies. Thousand Oaks, CA: SAGE Publications.

House Robert, J., P.J. Hanges, S.A. Ruiz-Quintanilla, P.W. Dorfman, M. Javidan, M. Dickson, V. Gupta and 170 co-authors, 1999. Cultural influences on leadership and organizations: Project GLOBE. In W. H. Mobley, M. J. Gessner \& V. Arnold (Eds.), Advances in global leadership, Stamford. CT: JAI Press, 1: 171-233. 